\title{
ANALOGÍAS ORGÁNICAS EN LA PROSA DE VALÉRY: EL INTELECTO Y LA CREACIÓN ARTÍSTICA
}

\author{
William Díaz Villarreal
}

\section{VALÉRY Y EL ORGANICISMO DE BERGSON}

En el discurso a la muerte de Bergson, de enero de 1941, Paul Valéry afirmaba que el legado del filósofo francés no sólo se debía a su evidente autoridad moral, sino también a la revolución que produjo en la historia del pensamiento. Bergson habría renovado los antiguos y complejos problemas del tiempo, la memoria y el desarrollo de la vida a través de la incorporación de un nuevo lenguaje a la filosofía. "Mientras la mayor parte de los filósofos seguían, desde el siglo XVIII, bajo la influencia de las concepciones físico-mecánicas, afortunadamente nuestro ilustre colega se dejó seducir por las ciencias de la vida. La biología le inspiraba" (Estudios filosóficos, p. 135; Euvres I, p. 884)․․ Ya que, como lo muestra M. H. Abrams en El espejo y la lámpara, el uso extensivo de la terminología de las ciencias de la vida comenzó en la estética y la psicología del siglo XVIII en Alemania (1971, p. 198-213), la observación de Valéry es más una confesión personal que una hipótesis objetiva. En efecto, la biología también inspiró a Valéry y su prosa crítica es, sin duda, un ecosistema exuberante de analogías orgánicas. No solamente los procesos sociales e históricos, sino también los fenómenos psicológicos y de la creación intelectual se asocian con el crecimiento de plantas, la nutrición de los animales, la maduración de semillas y el sabor de frutos.

${ }^{1}$ En el presente ensayo, cuando hay una traducción al español disponible, se ofrecen las referencias y números de página tanto de la traducción como del original francés. En estos casos, se cita la traducción y se indica si ha sido modificada. 
Por esta razón, muchos críticos contemporáneos vieron entre él y Bergson muchas afinidades que iban más allá de un lenguaje compartido. Thibaudet, por ejemplo, tradujo en cierto modo la filosofía del arte de Valéry al lenguaje de la metafísica bergsoniana. En un libro de 1923, afirmaba entre otras cosas que "la música que se adapta tan fluidamente a la metafísica de Schopenhauer y Bergson se encuentra en su lugar, como atmósfera y como símbolo, en torno al mundo de Valéry" (Thibaudet, p. 16). Aunque se cuida de afirmar una influencia directa, Thibaudet sugiere una profunda afinidad entre ambos. Si bien Valéry no es un filósofo ni Bergson un poeta, "metafísicamente, todo está en todo ", pues "hay intuiciones filosóficas en Valéry en la misma medida que las bellas imágenes de M. Bergson responden a intuiciones poéticas" (ibid. p, 22-23). En conclusión, aunque ambos se ignoran recíprocamente, parecen "expresar en dos lenguajes una intuición análoga" (ibid., p. 23).

Valéry no recibió con agrado estas observaciones de su amigo y de quienes sugerían vínculos semejantes. En una carta a Martin Gillet de enero de 1927 - que éste incorporó después como prólogo a su libro sobre el poeta-, escribía que Thibaudet se había equivocado al asociarlo a la doctrina bergsoniana del élan vital, que para él era "metafísica de primer orden" (Lettres à quelques-uns, p. 163). Más de una década después, el asunto parecía seguir intrigándolo, dada la cantidad de obras que insistían en los nexos entre los dos. "Llama la atención que se me haya querido derivar tantas veces de Bergson, pues todavía (agosto de 1941) no conozco su filosofía más que de oídas, y lo ignoraba completamente cuando me hice a mí mismo, entre [18]92 y 1900", escribe en sus cuadernos (Cahiers XXIV, p. 762). ${ }^{3}$ Valéry exagera, pues en realidad sí conocía la obra de Bergson, y no sólo de oídas: además de las frecuentes conversaciones que había sostenido con él, Valéry había leído La evolución creadora en 1924 o 1925 y por lo menos visto superficialmente Pensamiento y movimiento en 1934.

No obstante, es destacable la vehemencia con la que Valéry niega los posibles vínculos entre los dos, llegando incluso a afirmar que él nunca había leído a Bergson. En la carta a Gillet, sugiere que si lo hubiese leído en la época en que su pensamiento estaba modelándose, seguramente habría ejercido sobre él una influencia decisiva y lo habría conducido a una concepción metafísica de ciertos problemas fundamentales (Gillet, 1935, p. 8). Pero después de la década de 1890 el espíritu ya formado de Valéry rechazaba la metafísica, y por eso era inmune a las tentaciones de la filosofía

${ }^{2}$ En los casos en los que no existe o no se ha podido tener acceso a una versión en español del texto, las traducciones son mías.

3 Como en ésta, en todas las citas se han mantenido las expresiones en cursiva según el original, a menos que se indique explícitamente lo contrario. 
de la durée. El rechazo de Valéry a la influencia de Bergson tiene en este sentido algo de reactivo: ya que existen aspectos en común entre ambos, Valéry se veía en la obligación de delimitar el alcance de sus reflexiones, con el fin de distinguirse de toda metafísica y, en particular, de la del autor de $L a$ evolución creadora, que por entonces encarnaba el horizonte espiritual del pensamiento francés.

La afinidad más importante entre los dos aparece de hecho en el discurso de 1941. A Bergson, dice Valéry, "no le atemorizaba buscar en la observación de su propia conciencia algunas luces sobre problemas que nunca serán resueltos", y el esfuerzo de describir y comunicar el pensamiento propio exige "una aplicación particular e incluso la invención de una manera de explicarse adecuada a ese objetivo, pues el lenguaje expira en su propio origen" (Estudios filosóficos, p. 135; CEuvres I, p. 884-885). La principal tarea de Bergson consiste en reflejar el movimiento del propio pensamiento, en oponerse a las categorías tradicionales que dividen la realidad en conceptos estáticos. Éste afirma por ejemplo en Pensamiento y movimiento, de 1934, que el espíritu debe refundar sus categorías para adaptarse a una realidad móvil y cambiante. Los nuevos conceptos de la metafísica deben ser "fluidos, capaces de seguir la realidad en todas sus sinuosidades y de adoptar el movimiento mismo de la vida interior de las cosas" (Obras escogidas, p. 1105; Euvres, p. 1422).

Valéry, un escritor intensamente fascinado en la contemplación de sí mismo, comparte en principio esta aspiración de Bergson. Sin embargo, su lenguaje y sus analogías orgánicas apuntan en la dirección opuesta: "Me parece que Bergson se obstina en hacer fluido lo que yo me obstino en solidificar", escribe en un cuaderno de 1932 (Cahiers XV, p. 599). Esta afirmación de Valéry adquiere sentido si se contrastan sus ideas con las de Bergson. Éste sostiene en La evolución creadora (1907), por ejemplo, que "no hay diferencia esencial entre pasar de un estado a otro y persistir en el mismo estado", pues "el estado que 'permanece lo mismo' es más variado de lo que se cree" (Obras escogidas, p. 440; CEuvres, p. 496). Valéry, en cambio, afirma en una nota de 1900 que "el hecho elemental del intelecto es el cambio, que comprende sustituciones y transformaciones" (Cahiers I, p. 865; Robinson ed. Cahiers I, p. 878) ${ }^{4}$ y escribe en 1901 que "la única cosa continua es la noción de presente" (énfasis agregado. II, p. 275; I, p. 1263). Lo que su "colega ilustre

${ }^{4}$ La edición facsimilar en 29 volúmenes es considerada la edición estándar de los Cahiers de Valéry. Sin embargo, en 1973 Judith Robinson publicó también una selección en dos volúmenes (véase la bibliografía), mucho más accesible al público. En esta edición, sin embargo, Robinson recortó y clasificó las entradas según los temas y motivos que, en ocasiones, el mismo Valéry había seleccionado. Para facilitar el cotejo de las citas por parte del lector que no siempre tiene acceso a la edición facsimilar, cuando ha sido posible se han suministrado también los datos de las entradas en la edición de Robinson. 
y venerado" se representa como un fluir permanente, para Valéry es una sucesión de substituciones y transformaciones. Mientras que Valéry parte del supuesto de que los conceptos filosóficos más elevados son en realidad nociones de aplicación práctica, Bergson los concibe como realidades en sí mismas. Como afirma Judith Robinson, Bergson se deja "hechizar" por las palabras, cuando éstas no son más que abstracciones para Valéry ("Valéry critique de Bergson", p. 208). Por eso, aunque aquél se propone lo contrario, en realidad se atiene a las distinciones tradicionales que se han cristalizado en el lenguaje filosófico como convenciones. En una nota de los cuadernos, Valéry dice que cuando Bergson utiliza el término durée parece decir: "Encontré un procedimiento, un modo de pensar incomunicable, difícil para mí mismo, y otro que no sea yo nunca puede estar seguro de poseerlo idénticamente- y ahí está la Verdad" (Cahiers VI, p. 281; Robinson ed. Cahiers I, p. 549).

Valéry afirma que las ideas del filósofo francés son "combinaciones de elementos o términos que yo considero, para mí, arbitrarios, históricos - didácticos - y que yo no acepto sin una revisión y una reducción previas a principios redefinidos y reconocidamente útiles" (Cahiers XV, p. 504; Robinson ed. Cahiers I, p. 663). Por ejemplo, encuentra "singular" su distinción metafísica entre materia y vida (XIV, p. 103). Según La evolución creadora, la materia está sometida a las leyes naturales, cuyo principio básico está formulado esquemáticamente en la segunda ley de la termodinámica - "la más metafísica de las leyes de la física”, como la llama Bergson-: todos los cambios físicos tienden a degradarse en calor y éste tiende a distribuirse uniformemente entre los cuerpos (Obras escogidas, p. 647-648; Euvres, p. 70o701). La transformación del universo material - la forma básica de la durée - ocurre de tal manera que la inestabilidad y la riqueza que se nos manifiestan tienden hacia la estabilidad relativa de los elementos que lo componen. La materialidad nos brinda así la idea de "una cosa que se deshace". Ahora bien, si la desintegración se concibe como un movimiento descendente, "nuestra visión del mundo material es la de un peso que cae". Pero una de las formas de la materia es la vida, cuyo principio consiste precisamente en oponerse a esta tendencia. La vida es así "un esfuerzo [...] para remontar la pendiente que desciende la materia" (p. 649-650; p. 703)(ibid., p.649-650; ibid., p. 703). Aunque la vida no puede detener la marcha inexorable de la materia, intenta al menos retardarla. Toda la vida, en efecto, se guía por este impulso inicial - el élan vital- que consiste en acumular la energía que la materia tiende a disipar, para gastarla después de un modo relativamente instantáneo (ibid., p. 650-651; ibid., p. 703-704). 
Valéry, enormementeinteresadoen lascienciasexactas, estabaintrigado por una concepción similar. La vida en un planeta lejano sería, escribe por ejemplo en una nota a comienzos de la década de 1930, "una formación que lucha y juega con astucia con el principio de Carnot" (Cahiers XV, p. 442; Robinson ed. Cahiers II, p. 752). Más explícita es, sin duda, la siguiente definición en una nota sin título de 1902: "Frágil y tenaz — lo vivo. Efímero pero actuando contra la inercia eterna. Ella triunfa finalmente pero jamás actualmente" (II, ibid., p. 816; II, ibid., 721). ${ }^{5}$ No obstante, no llegaba tan lejos como Bergson, quien trataba de encontrar en la base de esta concepción un élan. Cuando la vida se concibe como un principio, dice Valéry, se cede ante la tentación de un espiritualismo negativo, pues se niega que ella esté ligada a condiciones "completamente numerables". Este espiritualismo se funda en la falacia de tomar por causa y agente de un fenómeno lo que, en la observación, se percibe como causado y como efecto. En términos rigurosos, en lugar de hablar de vida (vie), se debería hablar de "efecto de vida" (effet de vie) (ibid., XIII, p. 633; ibid., II, p. 749). La teoría del élan vital no encajaba en la estructura espiritual de Valéry, pues, como afirma en una nota de 1926-1927, "toda filosofía en la que la vida es un principio explicativo carece de valor para mí” (ibid., XII, p. 83; ibid., I, p. 623). Su imaginación se caracteriza por la aversión a toda forma de pensamiento que busque explicaciones fundamentales y últimas. Así, por ejemplo, escribe que no sabe si "la famosa 'durée' de Bergson" es una sensación, una percepción, un símbolo, una notación, una observación condensada o una metáfora. "Si no hay definición precisa, tampoco hay utilidad real", concluye (ibid., XV, p. 287; citado essa Robinson-Valéry, "Valéry critique de Bergson" p. 208).

Para Valéry, materia y vida no son principios metafísicos, sino conceptos y, como tales, están históricamente determinados. "La materia y la vida del año 1000 no son las mismas del año 1900, que tampoco con las del año 1937"(Cahiers XX, p. 217; Robinson ed. Cahiers I, p. 698). De hecho, el desarrollo de la física en el siglo XX ha puesto en duda la oposición en la que se basa la metafísica bergsoniana. "A la escala atómica, no hay seres vivos ni otros" (ibid., XIX, p. 148; ibid., II, p. 762). De este modo, es preciso asumir los descubrimientos de los físicos contemporáneos, abandonar la idea de la materia como un principio en dirección contraria a la vida y en cambio ver los seres vivos como sistemas dotados de un poder de conservación y renovación permanentes. En una nota de 1926 Valéry propone una relación entre la materia y la vida que, a pesar de compartir algunas cualidades con la idea de Bergson, apunta en una dirección opuesta.

${ }^{5}$ Ya que la traducción aquí ofrecida puede ser imprecisa, se adjunta el texto original: "Fragile et tenace - le vivant. Ephémère mais agissant contre l'éternelle inertie. Elle triomphe finalement mais jamais actuellement”. 
La vida es inseparable de la materia, pues ella no es más que una modificación de alguna materia - pero inseparable como una ola lo es del agua. No hay ola sin agua, pero tampoco hay ola del agua misma. (ibid., XI, p. 807; ibid., II, p. 743)

Valéry y Bergson están de acuerdo en que la vida es imposible sin la materia y que aquélla es, de hecho, una modificación particular de ésta. Sin embargo, en este símil no se presenta la oposición entre dos fuerzas metafísicas, ni se pregunta por un principio fundamental, sino que se sugiere que la vida es una forma, es decir, una estructuración particular de la materia que tiene una durée determinada, precisamente por estar en permanente renovación de sí misma. Además, todo objeto vivo se encuentra en un estado de "equilibrio estacionario", ya que parece luchar contra la presión que el medio ejerce sobre él. Así, por ejemplo, la llama sería, como afirma Valéry acerca del árbol y la planta, una imagen condensada de "la cosa viva elemental" (ibid., XI, p. 604; ibid., II, p. 742): ella "admite variaciones de la acción de las circunstancias exteriores, resiste las acciones que tienden a dispersarla, volviendo siempre a cierto valor" (ibid., VII, p. 338; ibid., II, 724). De hecho, "en esta llama se ven indicios de órganos. Aquí aspira ella el vapor y el gas que la alimentan; allí posee una superficie o una serie de camisas de diversas temperaturas por las que irradia el calor" (ibid., VII, p. 338; ibid., II, p. 725).

\section{LA ANALOGÍA COMO PRINCIPIO EPISTEMOLÓGICO}

La vida concebida como equilibrio estacionario y renovación permanente es una fuente inagotable de analogías. Son famosas, por ejemplo, las primeras oraciones de "La crisis del espíritu" (1919): "nosotras, las civilizaciones, sabemos ahora que somos mortales" y "sentimos que una civilización tiene la misma fragilidad que una vida" (Política del espíritu p. 21-22 ; Euvres I, p. 988). Ya que la fragilidad es intrínseca a la vida, es posible explorar analógicamente las condiciones objetivas que producen la enfermedad y la decadencia. Esta visión tiene la ventaja, en términos retóricos, de facilitar el despliegue de una analogía en una serie extensa de aspectos. Así, en la primera carta de "La crisis del espíritu", Europa aparece retratada como una mujer por cuya médula ha corrido la guerra como "un escalofrío extraordinario". Ella siente que no puede reconocerse a sí misma y que está a punto de perder la conciencia —una conciencia que, por lo demás, ha sido construida a lo largo de siglos de reflexión-. La intensa pasión con la que el público se entregó a la lectura y la explosión de la fe religiosa durante la guerra es como una defensa 
desesperada del ser psicológico de la dama, que ha hecho que toda su memoria se amontone confusamente en su cabeza: "Se ha evocado a todos los salvadores, fundadores, protectores, mártires, héroes, padres de patrias, santas heroínas, poetas nacionales..." (ibid., p. 23; ibid., p. 989).

Como se puede ver, Valéry extiende en dos series paralelas la crisis de la dama y la crisis del espíritu europeo, de manera que los síntomas de la primera y los de la segunda se interpenetran permanentemente. En un párrafo que, como es obvio, termina en puntos suspensivos, menciona los "innumerables pensamientos" que Europa evoca en su desorden mental (ibid., p. 23; ibid., 989-990); luego diferencia tres dimensiones de la crisis —la militar, la económica y la intelectual- (ibid., p. 24; ibid., 990); después enumera atropelladamente los hechos "claros y despiadados" que no permiten ser optimista frente a la condición de la enferma, desde la muerte de miles de escritores, hasta las vacilaciones de los escépticos (ibid., p. 2425; ibid., p. 990-991). El ritmo casi atropellado de estas enumeraciones y vacilaciones conduce a una conclusión que, en cierto modo, es inevitable. El delicado estado de la paciente se debe a aquello que hace que la actual crisis del espíritu sea profunda y grave, pero diagnosticarlo con precisión es casi imposible, ya que demandaría "conocimientos de todos los órdenes, una información infinita” (ibid., p. 25; ibid., p. 991).

La expansión del fenómeno de la crisis europea a través del principio analógico tiene también una ventaja implícita en este ensayo de Valéry que otros textos muestran con más claridad. En su estudio sobre Svedenborg (1937), afirma que "toda descripción de nuestras percepciones separadas destruye radicalmente aquello que sería lo más preciado de conocer y de descifrar en nuestras percepciones" (Estudios filosóficos p. 129; Euvres I, p. 880). Esta crítica a la descripción analítica como método del conocimiento también se podría vincular con Bergson, quien afirma en Pensamiento y movimiento que mientras que el análisis inmoviliza los fenómenos, la intuición se pone a sí misma en la movilidad y por eso permite una visión más genuina de la realidad (Obras escogidas, p. 1096; CEuvres 1412). Pero Valéry evita el entusiasmo de su amigo por la intuición, pues ella no proporciona, en el mejor de los casos, más que una imagen vaga de una realidad demasiado compleja. En el ensayo sobre la crisis del espíritu europeo, dice que si uno hace abstracción de todo detalle, la "totalidad natural" (le total naturel) que se nos presentaría a la percepción inmediata es una "nada", aunque esta nada sea infinitamente rica. Valéry explica esta cuestión por medio de otra analogía. El intelecto, dice, es como el ojo en un medio altamente incandescente: no puede distinguir las diferencias y por lo tanto los objetos, pues no hay desigualdad alguna en la intensidad de la luz (Política del espíritu p. 25; CEuvres I, p. 991). 
Este principio, además de mostrar lo complejo de la condición de la cultura europea, tiene también una gran utilidad epistemológica y retórica. La visión de una totalidad natural compleja (desde la cultura europea hasta un árbol, una planta o la llama de una vela) sólo tiene sentido para Valéry cuando se concibe como un ensamblaje potencialmente rico de articulaciones formales. Las analogías se encuentran pues en el corazón del pensamiento de Valéry, precisamente porque buscan escapar tanto de la desintegración analítica de los fenómenos en unidades desconectadas, como de la intuición inmediata, vaga y general de una totalidad natural. Ellas son el instrumento de la actualización de lo que la imagen instantánea presenta en potencia; posibilitan saltos del pensamiento que, por decirlo así, preservan el fenómeno singular como una totalidad compacta, pero también arrojan sobre él una luz cambiante que ilumina aspectos que se encuentran ocultos a primera vista.

\section{EL ÁRBOL, LA ARAÑA Y EL MONSTRUO}

El principio retórico que guía el pensamiento de Valéry consiste pues, como él mismo escribe en 1922, en una permanente transformación "que se asemeja a la del análisis y que resulta de la actividad espontánea de las analogías" (Cahiers VIII, p. 676). Así como algunos procesos culturales, la creación artística también es susceptible de desenvolverse analógicamente a través de los procesos orgánicos. En este caso, ya que la idea de la vida significa renovación permanente y equilibrio estacionario, la nutrición es una imagen recurrente. En un fragmento de Tel quel, por ejemplo, Valéry afirma a propósito de la originalidad artística: "Nada más original, nada más propio de uno mismo que el nutrirse de los demás. Ahora bien, hay que digerirlos. El león está hecho de cordero asimilado" (Tel quel p. 17; Euvres II, p. 478). Asimismo, la "Figura prodigiosa" de Goethe, dice en el ensayo en su honor, es "un monstruo de comprensión y de fuerza creadora", que "habiendo hecho suyo, habiendo devorado, habiendo transformado en obras inmortales todo lo que una experiencia humana ha podido en su carrera acoger o estrechar, y metamorfosear, es finalmente él mismo metamorfoseado en Mito" (Estudios literarios p. 115; Euvres I, p. 534). No sólo las grandes obras son el producto de un metabolismo que se asemeja al de la producción del fruto en una planta, también los grandes artistas tienen la propiedad de lo orgánico de crearse a sí mismos. Pero, como Valéry agrega, "el sabor de los frutos de un árbol no depende del aspecto del paisaje que lo rodea, sino de la invisible riqueza del terreno". En esta imagen, el paisaje corresponde a 
la biografía del autor, a aquellos acontecimientos externos a la creación que no nos permiten conocer lo verdaderamente importante, que hace único: "la verdadera operación de su espíritu", donde se encuentra su profunda e invisible riqueza (ibid., p.114; ibid., p. 533).

Ahora bien, como afirma Christine Crow, la analogía de la planta presenta el proceso intelectual como una forma de crecimiento (Paul Valéry. Consciousness and Nature p. 230). Para Valéry, el crecimiento orgánico implica la continuidad y la expansión temporal de un orden a través del despliegue de ciertas similitudes interiores elementales. En Diálogo del árbol (1943), Lucrecio no sólo afirma que "lo más alto de la inteligencia no vive sino de crecer"; también dice que "si alguien en el mundo medita, es la Planta". Meditar, aclara, es "sumirse más a fondo en el orden": en un árbol, la vida "calcula, agota una estructura, e irradia su número por ramas y tallos, y cada tallo su hoja, en los precisos puntos señalados del futuro naciente" ("Diálogo...” p. 167-169; Euvres II, p. 191193). La meditación del árbol es una forma de cálculo y construcción de una estructura simétrica que se ramifica permanentemente. El crecimiento intelectual se rige por leyes similares, pues en lo más íntimo de nuestro espíritu poseemos el mismo poder que produce la vida (ibid., p. 164; ibid., p. 187). "Me siento vivir la inaudita empresa del Tipo de la Planta", dice Lucrecio (ibid., p. 168; ibid., p. 192).

En términos generales, los mecanismos del crecimiento y la acción del intelecto son asimilables al árbol del siguiente fragmento de Mélange:
Oh, planta, árbol, repetición radiante,
Tu irradias tu edad por temporadas y por gérmenes
Repites tu motivo regularmente en cada ángulo
De cada etapa de tu estatura creciente, y repites
Tu esencia en cada grano, te produces, desembocas
periódicamente en torno tuyo bajo la forma de la probabilidad -
en tal número
Eliminas tus similitudes (Euvres I, p. 353$)^{6}$

De acuerdo con Crow, las nociones de arquitectura y simetría, de creación de orden a partir de un desorden inicial, juegan un papel central en el pensamiento de Valéry. El árbol tiene la capacidad no sólo de combinar elementos individuales como un arquitecto, sino también

6 "Ô plante, arbre, répétition rayonnante, / Tu rayonnes ton âge par saisons et par germes / Tu répètes ton motif régulièrement à chaque angle / De chaque étage de ta croissante stature, et tu répètes / Ton essence en chaque graine, tu te produis, tu te jettes / Autour de toi périodiquement sous forme de chances - / en tel nombre / Tu élimines tes similitudes". 
de transformarlos en su propia sustancia (CROW, 1972, p. 231-232). Así, el espíritu de Leonardo, por ejemplo - el modelo de ese posible que Valéry concibe para sí mismo-, tiene muchos aspectos que coinciden con las descripciones de la planta: un monstruo de transformaciones que se expande a partir de su propio centro (Escritos sobre Leonardo... p. 16; CEuvres I, p. 1154), un sistema completo en sí mismo (ibid., p. 41; ibid., p. 1179) cuya continuidad se basa en la aplicación de combinaciones regulares (ibid., p. 34; ibid., p. 1172), una fuerza en expansión cuyos límites están en la naturaleza (ibid., p. 15; ibid., p. 1153), etc.

Según Crow, aunque para Valéry la planta es comparable con una máquina, él prefiere el modelo orgánico para describir el desarrollo intelectual del artista, pues le permite mantener el elemento de misterio que sugiere una existencia que se renueva a sí misma como interioridad pura (op. cit., p. 229-230). Estas afirmaciones, en principio correctas, dejan de lado un aspecto fundamental cuya importancia no puede soslayarse. Aunque la planta es un sistema más complejo que la máquina, y ello la hace más conveniente para ciertos propósitos argumentativos, el despliegue analógico del organismo también se rige por algunos principios mecánicos de la física y la termodinámica. En otras palabras, Valéry supone que eso que Crow llama un "elemento de misterio e inevitabilidad" de lo orgánico también puede expandirse analógicamente a través de fenómenos mecánicos. El misterioso encanto de la planta se encuentra en su capacidad para perpetuarse y ramificarse a través de la repetición y la renovación de sus propias similitudes, y estos procesos pueden representarse con imágenes tomadas de la física, la termodinámica y la geometría. Hay pues un fondo de cibernética en las analogías orgánicas de Valéry, quien ve los procesos intelectuales como guiados en parte por la lógica de sistemas mecánicos de control, regulación, comunicación y acción a distancia. ${ }^{7}$ Este principio retórico tiene también una motivación teórica, pues las analogías mecánicas proporcionan imágenes precisas, "figuras sensitivo-motrices" que permiten formar grupos de problemas teóricos y esquemas mentales de operación. Estos esquemas son, por lo

7 El "enfoque cibernético" de las reflexiones de Valéry se convirtió en moneda corriente en la investigación entre 1960 y 1990, en particular después de la publicación de los Cahiers y del estudio de Judith Robinson-Valéry, L'Analyse de l'esprit dans les Cahiers de Valéry. Entre otros trabajos que se ocuparon tangencialmente del tema, cabe destacar los ensayos de Jeannine Jallat ("Valéry et le mécanisme: la notion de modèle et la théorie de la construction" y "Valéry and the Mathematical Language of Identity and Difference”), el libro Paul Valéry, linguiste dans le Cahiers de Jürgen Schmidt-Radefeldt, así como los textos de diversos autores reunidos en Fonctions de l'esprit, editado por Judith Robinson-Valéry y Pierre Auger. 
demás, "maniobras mentales" que le muestran al espíritu “aquello que un hombre puede' en toda materia", como dice Valéry en 1941 (Cahiers XXV, p. 328; Robinson ed. Cahiers II, p. 908). En este sentido, el despliegue de las analogías tiene un valor práctico, pues integra el conocimiento a la praxis humana, a la capacidad de incorporar los fenómenos externos en el ámbito de las cosas asimilables por el espíritu.

Crow también sostiene que la planta como modelo del intelecto no sólo es más rica y compleja que el mecanismo, sino que presenta ventajas frente a otros organismos superiores. La planta muestra con suficiente claridad "la coexistencia de la espontaneidad y la limitación, el desenvolvimiento espontáneo desde adentro de un diseño potencial inherente" (Crow, op. cit., p. 230). Sin embargo, vale la pena destacar la pasión con la que Valéry se representaba al intelecto como un animal. Si la planta hace explícita la coexistencia de la espontaneidad y la autolimitación del intelecto, los animales le sirven a Valéry precisamente para mostrar cualidades de la creación artística que se encuentran más allá del simple desenvolvimiento espontáneo de un diseño potencial. Cuando Valéry afirma que el león es cordero digerido, no solamente se refiere al proceso biológico de asimilación y apropiación de lo extraño, sino que apela al mismo tiempo a los contenidos semánticos implícitos en la imagen del animal que una planta no puede ofrecer con la misma inmediatez.

Igualmente, la comparación que hace Émilie del trabajo del intelecto de su esposo, el famoso Monsieur Teste, con el de una araña que teje una tela delicada insinúa la presencia de una voluntad, un poder y una paciencia incorruptibles (Monsieur Teste, p. 58; CEuvres II, p. 29). También hay otra araña en "A propósito de Adonis" (1921) sobre la que vale la pena hacer algunas observaciones:

\footnotetext{
Imagino yo a ese poeta, como un espíritu lleno de recursos y de artificios, simulando estar dormido en el centro imaginario de su obra, todavía por crear, para llegar mejor a ese instante de su propio poder, que constituye su presa. En la difusa hondura de sus ojos, todas las fuerzas de su deseo, todos los resortes de su instinto están tensos. Allí, atenta a los azares entre los que habrá de escoger su alimento; allí, oscura, en medio de las redes y de las secretas arpas y trampas que se ha construido con el lenguaje, cuyos entramados se entretejen y vibran vagamente, una Aracné misteriosa, musa cazadora, acecha. (Estudios literarios 67, traducción modificada; Euvres I, p. 484).
}

En primer lugar, cabe destacar la actitud expectante de esta Aracné en el centro de su obra en estado de potencia, pues integra las ideas de tensión y espera a la esfera del puro crecimiento orgánico. La obra 
no surge naturalmente en el poeta como la semilla que se convierte en una planta, sino que la conciencia cumple un papel activo: de manera casi instintiva está a la espera del momento en el cual su propia fuerza imaginativa hará surgir el germen del que se desarrollará la obra. La imagen también sugiere una problemática que ocupó constantemente a Valéry: la red que teje esta criatura está hecha de lenguaje, un material delicado que vibra "vagamente". Las relaciones y combinaciones de símbolos de la lengua son, en el espíritu del poeta, el material básico de su construcción. ${ }^{8}$ Por otro lado, entre la mente del poeta "llena de recursos y de artificios" y la imagen final de la "musa cazadora” Aracné hay una permanente metamorfosis analógica que sintetiza los momentos de la psicología de la creación artística como una totalidad: la oscuridad -que sugiere la profundidad e inaccesibilidad del trabajo intelectual por medio de la conciencia-, el tejido construido a partir de las formas del lenguaje, la espera acechante del momento propicio, la intervención del azar, la concentración de toda la energía intelectual en la creación y, finalmente, el hecho de que la conciencia no es simplemente una araña, sino que se hace visible a través de una figura mitológica, es decir, de un símbolo humanizado. ${ }^{9}$

Esta metamorfosis del intelecto tiene como correlato una especie particular de "animal" que nace - y muere casi inmediatamente - con asombrosa frecuencia en la prosa de Valéry. Según "Una pequeña carta sobre los mitos" (1928), cualquier fisiólogo podría demostrar que una sirena es anatómicamente imposible; sin embargo, "un monstruo o una quimera, que no son viables en la realidad, se encuentran a sus anchas en la vaguedad de las mentes" (Estudios filosóficos, p. 237; CEuvres I, p. 964). El monstruo es así para Valéry el arquetipo orgánico de una existencia puramente intelectual y por lo tanto fisiológicamente imposible, una créature excepcionnelle que la mente puede producir en un momento excepcional. Valéry utiliza la palabra monstre en un sentido similar,

${ }^{8}$ Valéry se ocupó del problema del lenguaje como material básico de la poesía, y de su diferencia con los materiales de otras artes - por ejemplo el sonido en la música o la roca y el espacio en la arquitectura-, en la mayoría de sus textos sobre teoría poética. Los ensayos más importantes son quizás su prólogo al libro Connaissance de la déesse (1920) de Lucien Fabre, "Cuestiones de poesía" (1935) y el famoso "Poesía y pensamiento abstracto" de 1939 (Teoría poética..., p. 25-42 y p. 71-103; CEuvres I, p. 1269-1294 y p. 1314-1339).

${ }_{9}^{9}$ Cabe aclarar al margen que, según la mitología grecorromana, Aracné no era musa ni cazadora. Era en cambio, una tejedora hábil que incluso llegó a retar a Palas Atenea, su maestra. Para algunos, ella es la inventora del arte del tejido, para otros, el símbolo de la ingratitud (véase HEDERICH, p. 351-352). Al convertirla en musa, Valéry la asocia con la producción artística, y al mostrarla como cazadora, acentúa el papel activo que juega en la creación. 
aunque en un contexto diferente, en la "Nota y digresión" de 1919 a su ensayo juvenil sobre Leonardo. La base de su argumento es que existe una tensión entre la tendencia de la conciencia a devenir universalidad pura, por un lado, y los límites que le impone la muerte a esa universalidad, por el otro (Escritos sobre Leonardo..., p. 85-87; CEuvres I, p. 1217-1219). Ya que "el conocimiento no conoce límites", la propia muerte es para la conciencia un desastre incomprensible que no puede representarse directamente. Para tratar de superar esa incapacidad inherente $-\mathrm{y}$ en cierto modo prepararse para su propia desaparición-, la conciencia crea, siguiendo sus propias leyes interiores, mundos inestables e inhumanos, tormentos y sensaciones extraordinarias. Aquí yace el origen de ciertas formas de la sensibilidad que el sujeto posee. Ellas "no pueden tener éxito, pero [...] pueden nacer. Son instantes arrebatados a la implacable crítica de la duración" y no resisten el funcionamiento completo de nuestro ser. Estas formas son "monstruos [...] llenos de lecciones" y al mismo tiempo "estados de tránsito" en los que las conexiones lógicas normales son alteradas (ibid., p. 88-89; ibid., p. 1220-1221). De nuevo, lo monstruoso designa aquí figuras esencialmente inestables cuya existencia concreta es imposible, estados aberrantes puramente intelectuales. ${ }^{10}$

${ }^{10}$ En "A propósito de Adonis", Valéry se refiere a las figuras monstruosas en la historia del arte y la cultura desde una perspectiva un tanto diferente, aunque no carece de interés. El monstruo que aparece en el poema de La Fontaine es sin duda "terrible", dice, pero más terrible es la tarea de describirlo. Ello se debe a que los monstruos en el arte son siempre figuras ridículas, afirma refiriéndose entre otros a la ballena de Jonás — que, en una versión más reciente, también se traga a Simbad—, al "extravagante animal complejo" que Rugiero atraviesa con su lanza en Rugiero liberando a Angélica, de Ingres, y a otros monstruos más humanos, como los cíclopes y Cuasimodo, el jorobado de Hugo. Sobre estos últimos afirma que "el complemento necesario de un monstruo es un cerebro de niño". Los seres grotescos que aparecen en la historia de la pintura, dice a continuación, son como "los grabados de la moda anatómica". Estas figuras nos parecen hoy imposibles, pues "no creemos en seres tan extravagantes, y nos escapamos de su realidad mediante el sentimiento de su improbabilidad y de su consideración como un desmañamiento y una tontuna primitivos que sólo con la risa son mensurables" (Estudios literarios p. 7273; Euvres I, p. 490-491). Más allá de la idea de la risa como respuesta instantánea a lo que en nuestra cultura vemos como bestialidad primitiva, vale la pena notar un vínculo tangencial con las afirmaciones de Valéry sobre la existencia intelectual de los monstruos. Desde un punto de vista histórico, ellos constituyen la encarnación extrema de lo posible o lo concebible en un momento determinado. Pero dado que las condiciones materiales son siempre cambiantes, estas criaturas infernales tienen una vida histórica breve o, mejor, muy pronto dejan de ser puramente espantosas y los seres humanos las encuentran grotescamente ridículas. En otras palabras, lo monstruoso y anormal no tiene solamente una corta vida biológica; su vida histórica también es breve. 
Los monstruos son también la encarnación de todo modelo del intelecto como potencia creadora. Posiblemente una de las criaturas aberrantes más destacadas es Teste, prototipo de la vida intelectual del propio Valéry, a quien su creador describe como una figura imposible cuya existencia "no podría prolongarse en lo real por más de algunos cuartos de hora". Sin embargo, el problema de una existencia semejante constituye un germen de aquellos seres que no pueden desarrollarse. Son seres anormales, pues sus propias contradicciones los destruyen inexorablemente. En otras palabras, "son semejantes a muchos pensamientos que incluyen contradicciones ocultas. Estas se producen en la mente; parecen exactas y fecundas, pero sus consecuencias las arruinan y su presencia pronto les es funesta " (Monsieur Teste p. 19-20; Euvres II, ibid., p. 13). Teste es así "el demonio mismo de la posibilidad" (ibid., p. 21; ibid., p. 13), pues se presenta como un modelo biológico y cibernético de la acción del intelecto sobre el mundo, aunque su existencia concreta sea biológicamente imposible. La imagen del monstruo no sólo condensa así el carácter virtual y potencial de todo prototipo del intelecto, sino que sirve de crítica a las limitaciones de las analogías orgánicas. El espíritu humano tiene una profunda dimensión biológica que permanece oscura para la conciencia. Sin embargo, la acción del intelecto no es esencialmente orgánica, sino que implica un momento de actualización, es decir de actuación sobre la realidad, que las analogías de la planta o el animal no pueden iluminar.

\section{ARTE Y NATURALEZA: EL MOLUSCO Y EL INGENIERO}

Por eso, uno de los asuntos que más ocupó a Valéry fue la inconmensurabilidad entre los objetos naturales y las obras humanas. También aquí se distingue de Bergson, quien en la primera parte de $L a$ evolución creadora, por ejemplo, afirma que "el arte vive de la creación e implica una creencia latente en la espontaneidad de la naturaleza” (Obras escogidas, p. 477; (Euvres, p. 533). Aunque Bergson admite que somos artistas al mismo tiempo que somos artesanos, también sugiere que el arte se encuentra más del lado de la intuición inmediata y de la naturaleza espontánea que de las similitudes y las repeticiones mecánicas, pues no es otra cosa que la forma más sublime del principio básico de la vida. "No somos la corriente vital misma; somos esta corriente ya cargada de materia”. Nuestras obras artísticas son actos de creación sobre la materia que elevan, por decirlo así, el principio creativo que anima a la vida misma. En la composición de una œuvre géniale - así como en un acto 
libre - extendemos "el resorte de nuestra actividad" y buscamos crear lo que "ninguna reunión pura y simple de materiales" podría producir (ibid., p. 644; ibid., p. 698).

Valéry, en cambio, postula una diferencia insalvable entre la naturaleza y el arte. Seguramente el ensayo emblemático sobre este asunto es "El hombre y la concha" (1937), en el que una concha a la orilla del mar deviene un objeto misterioso que Valéry pretende descubrir por primera vez. Los innumerables pensamientos que provoca se derivan de una pregunta básica: “QQuién ha hecho esto?”." Esta pregunta ingenua es, dice Valéry, la más inmediata de todas; también es la más humana, pues al fin y al cabo el hacer es la idea más íntima de nuestra especie. En efecto, “explicar' no es otra cosa que describir una manera de Hacer: no es más que rehacer mediante el pensamiento" - y la ciencia y la metafísica no son más que el despliegue sin limitaciones de las exigencias que impone esta idea- (Estudios filosóficos, p. 144-145; Euvres I, p. 891). Preguntarse por el que hizo la concha no consiste en averiguar cuál es el animal particular que la fabricó, sino comprender la fuerza secreta que guía el proceso constructivo en todos sus momentos. Igual ocurre con las obras de arte, dice Valéry, expresando así uno de sus principios teóricos básicos - por medio de una analogía-. La respuesta a la cuestión de quién ha hecho cierta obra no consiste en saber el nombre del compositor, el artista o el poeta a quien se le adjudica, pues estos nombres no dicen gran cosa; un nombre determinado - por ejemplo, Mozart o Virgilio - apenas selecciona a una persona en particular entre toda la humanidad, pero deja sin resolver el enigma de aquello que, viviendo en su espíritu, crea (ibid., p. 145-146; ibid., p. 891).

Para indagar por el hacedor de la concha hay que estudiar las condiciones de su forma e inferir el proceso de fabricación. Si se la compara, por ejemplo, con una piedra, se observa que en ésta no hay coincidencia entre el todo y las partes. "Los fragmentos de la concha no son conchas; pero los fragmentos de piedra son otras tantas piedras, lo mismo que [ella] lo era seguramente de alguna otra más grande" (ibid., p. 146; ibid., p. 891). Las partes de la concha, en cambio, parecen relacionarse unas con otras de acuerdo con una idea que les es externa. "Algunos fragmentos de la concha

${ }^{11}$ Es por lo demás evidente que este ensayo es, en muchos aspectos, una escenificación posible del encuentro de Sócrates con un objet ambigu en el diálogo Eupalinos o el Arquitecto publicado en 1921 (VALÉRY, “Eupalinos...” p. 120 y ss.; CEuvres II, p. 116 y ss.). Para un análisis de este diálogo, véase el hoy clásico ensayo de Hans Blumenberg, (2001, p. 74-111), "Sokrates und das 'objet ambigu'. Paul Valérys Auseinandersetzung mit der Tradition der Ontologie des ästhetischen Gegenstandes” (BLUMENBERG, 2001, p. 74-111). 
me sugieren la forma de los que se les yuxtaponían: incitan de algún modo mi imaginación, inician un desarrollo progresivamente; piden un todo" (traducción modificada). Este todo no es otra cosa que la idea que rige la estructura y la composición de la concha, la "idea preexistente, bien separada de la obra misma" que permite, por otro lado, que la obra sea construida por acciones sucesivas (ibid.. p. 146-147; ibid.. p. 893). Por eso, es fácil imaginar que ha sido hecha y que, por lo tanto, puede ser fabricada por el hombre.

El ensayo de Valéry está estructurado a partir de la oposición entre una concha natural, construida por el molusco a partir de una materia segregada por su propio cuerpo, y una artificial, hecha por un constructor imaginario. Supongamos, dice Valéry, que queremos fabricar el objeto; en este caso, tendríamos que escoger un material determinado y, de acuerdo con las condiciones objetivas que éste nos impone, proceder a la fabricación. Una concha de yeso, por ejemplo, requiere operaciones diferentes de las que requiere una de bronce o de piedra; los procedimientos son diversos, aunque la idea de la forma es la misma. De aquí deduce Valéry uno de los principios más fructíferos en su estética. Si el constructor imaginario puede escoger entre una variedad de materiales, es porque en su mente la forma no está indisolublemente ligada al material.

El ser humano actúa sobre la materia por gestos sucesivos, separados, limitados y numerables (ibid.. p. 149; ibid. p. 896), de modo que, por ejemplo, el material y la forma de un objeto artificial son, desde el punto de vista humano de la construcción, independientes. Así, el sujeto no puede imaginar, por ejemplo, un material enteramente determinado por las condiciones que exige la forma del objeto. La ventaja de esta separación de los momentos de la construcción es que la idea que el constructor se hace de la forma le permite concebir una enorme cantidad de posibilidades, no sólo de materiales, sino también de tamaños, por ejemplo. Por eso, una figura determinada tiene, en el espíritu humano, cierto poder para generar una serie enorme de figuras que le son semejantes, aunque sean diferentes en su material, en su proceso de producción y en las relaciones de tamaño entre las partes (ibid. p. 148; ibid. p. 894). Este poder no es otra cosa que la libertad humana frente al objeto producido.

El molusco, en cambio, no posee tal libertad, pues no separa los momentos de la fabricación, sino que segrega la concha del mismo modo que "una gruta segrega sus estalactitas" (ibid. p. 152, traducción modificada; $i d$. p. 898). Los momentos que el ser humano abstrae en el proceso total de la construcción están, en el trabajo del molusco, integrados en una continuidad total de relaciones y transformaciones 
completamente determinadas por la naturaleza del molusco mismo él sólo existe, por decirlo así, en cuanto productor de la concha-. De hecho, los defectos de ésta, debidos por ejemplo a pequeños accidentes de la construcción, se integran en la continuidad formal y material de la fabricación. La concha de origen natural es un todo continuo en cuya elaboración la forma, la materia, el tamaño y el procedimiento responden a una necesidad absoluta: en términos crudos, una concha es como es porque el molusco no pudo haberla hecho de otro modo.

Esta diferencia entre la producción natural y la humana es también el índice de la distancia que separa a los hombres de los animales y, en general, de la naturaleza viva. "Si no se puede hacer más que una cosa, y de una sola manera, se hace como por sí misma; y por lo tanto dicha acción no es verdaderamente humana (porque el pensamiento no es necesario), y nosotros no la comprendemos" (ibid.p. 148; ibid.p. 895). El campo deacción del intelecto humano es extremadamente limitado, pues se desarrolla en el ámbito de los fines, que es ajeno a la vida natural. Sin retocarla, sin arrepentirse y siempre concentrado en ella, el molusco produce su concha y nosotros no podemos imaginar por qué, por ejemplo, la ha fabricado en la dirección contraria a las manecillas del reloj. La abstracción del hombre sobre la materia lo conduce, por ejemplo, a preguntarse por la "utilidad" de hacer las conchas como una hélice izquierda, como tiende a hacerlas la mayoría de los moluscos, "sin pensar que nuestra idea de lo útil carece de sentido fuera del hombre y de su pequeña esfera intelectual" (ibid. p.155; ibid. p. 9oo). A pesar de gozar de una mayor libertad frente a su obra, el artista, como todo constructor, debe concebir fines y enfrentarse a la cuestión de la utilidad de los momentos de la elaboración. Por eso, debe comprometerse con las limitaciones que le imponen los materiales, calcular formas y tomar decisiones que, de hecho, no pueden desplegarse con la analogía del crecimiento natural.

No obstante, hay una relación especial entre la producción humana y la naturaleza que sostiene toda la teoría estética de Valéry. El artista no produce orgánicamente la obra, como pensaba Bergson, por el impulso profundo y secreto de la vida en su interior. Si fuera así, el artista la segregaría como un molusco segrega su caparazón. Sin embargo, el ideal de la obra de arte perfecta es el de un producto que se realiza a sí mismo, como los objetos naturales. En palabras de "El hombre y la concha":

Tal vez lo que llamamos la perfección en el arte (que no todos buscan y más de uno desdeña) no es otra cosa que el sentimiento de desear o de encontrar, en una obra humana, esa certeza en la ejecución, esa necesidad de origen interior, y esa relación indiscutible y recíproca de la figura con la materia que la concha más pequeña me hace ver (ibid. p. 160; ibid. p. 904-905). 
Esta perfección es evidentemente irrealizable para el hombre, pero su labor en cuanto artista consiste en imitarla en el procedimiento mismo. Valéry afirma por ejemplo, en "Bordados de Marie Monnier" (1924), que el hombre imita la paciencia de la naturaleza en la producción de aquellas cosas preciosas que "se forman por acumulación de infinidad de sucesos imperceptibles y aportaciones elementales, que consumen un tiempo muy largo y exigen tanta calma como tiempo"; entre estas cosas se encuentran "las perlas finas, los vinos generosos" y "las personas verdaderamente logradas” (Piezas sobre arte ibid. p. 93; Euvres I, ibid. p. 1245). Aunque la naturaleza sirve de horizonte ideal de la actividad humana, Valéry no olvida que se trata de una imitación de la paciencia de la naturaleza, no de la pura expresión de la naturaleza en las obras humanas. En este sentido, la búsqueda del ideal del arte es una forma de reflexión, un proceso por el que, sabiéndose diferente de la naturaleza, el ser humano busca imitar su poder creador.

Valéry da así una vuelta de tuerca a la distinción bergsoniana entre el artista, impulsado por el poder creador de la naturaleza, y el artesano, que calcula y repite operaciones similares sobre la materia. Valéry admite con Bergson que en la creación artística hay un momento de construcción y de cálculo independientes del puro crecimiento orgánico. No obstante, también sugiere que el crecimiento orgánico es en muchos sentidos un despliegue de similitudes y repeticiones mecánicas: en los términos de Bergson, que en cuanto seres naturales también somos artesanos y no simplemente artistas. No sólo el árbol se renueva en sus propias similitudes, también el molusco se asemeja al constructor, pues su obra no es, como una piedra, una totalidad homogénea, sino que parece responder a una idea que le es externa. Las analogías orgánicas sugieren una renovación permanente de una forma, y sobre todo sirven de modelo para aquellos procesos inconscientes, íntimos y hasta cierto punto oscuros para el intelecto que actúan en la creación artística. Sin embargo, en tanto constructor, el artista debe actuar según la ley de la separación abstracta de los momentos que constituyen la totalidad del acto creativo. Así, su espíritu deviene un ser fabuloso que crece como una planta, tiene la voluntad ciega de un animal y debe traducir la potencia de un monstruo de transformaciones en actos singulares, repetibles, medibles y combinables. El resultado de todos estos momentos que se superponen permanentemente es la obra artística, que Valéry describe también como una máquina de transformaciones. Pero la descripción de esta máquina fabulosa moviliza todo un campo de analogías que no son orgánicas y superan el objeto del presente ensayo. 


\section{Villarreal - 119 \\ BIBLIOGRAFÍA}

ABRAMS, M. H. The Mirror and the Lamp. Londres: Oxford University Press, 1971.

BERGSON, H. Obras escogidas. Tr. José Antonio Miguez. México: Aguilar, 1959.

BERGSON. Euvres. Ed. André Robinet. París: Presses Universitaires de France, 1970.

BLUMENBERG, H. Ästhetische und metaphorologische Schriften. Ed. Anselm Haverkamp. Frankfurt am Main: Suhrkamp, 2001.

CROW, C. M. Paul Valéry. Consciousness and Nature. Cambridge: Cambridge University Press, 1972.

GILLET, M. S. Paul Valéry et la métaphysique. París: Flammarion, 1935.

HEDERICH, B. Gründliches mythologisches Lexikon. Leipzig: Gleditsch, 1770; Darmstadt: Wissenschaftliche Buchgesellschaft, 1967.

JALLAT, J. Valéry and the Mathematical Language of Identity and Difference. Yale French Studies, n. 44. 197. p. 51-64.

JALLAT. Valéry et le mécanisme : la notion de modèle et la théorie de la construction. Saggi e ricerche di letteratura francese, $n$. VIII. 1967: p. 185-241.

ROBINSON-VALÉRY, J. L’Analyse de l'esprit dans les Cahiers de Valéry. París: Corti, 1963.

ROBINSON-VALÉRY. Valéry critique de Bergson. Cahiers de l'Association Internationale des Études Françaises, n. 17. 1965: p. 203-215.

ROBINSON-VALÉRY. y P. Auger, eds. Fonctions de l'esprit : treize savants redécouvrent Paul Valéry. París: Hermann, 1983.

SCHMIDT-RADEFELDT, J. Paul Valéry linguiste dans le Cahiers. París: Éditions Klincksieck, 1970.

THIBAUDET, A. Paul Valéry. París: Bernard Grasset, 1923.

VALÉRY, P. Cahiers. 29 vols. Edición facsimilar. París: Centre National de la Recherche Scientifique, p. 1957-1961.

VALÉRY, P. Cahiers. Édition établie, présenté et annotée par Judith Robinson-Valéry. 2 vols. París: Gallimard, p. 1973-1974.

VALÉRY. Diálogo del árbol. In: Mi Fausto. Diálogo del árbol. Tr. José Luis Arántegui. Madrid: Visor, 2003. p. 151-170.

VALÉRY. P. Escritos sobre Leonardo da Vinci. Tr. Encarna Castejón y Rafael Conte. Madrid: Visor, 1987.

VALÉRY. P. Estudios filosóficos. Tr. Carmen Santos. Madrid: Visor, 1993. 


$$
120 \text { - Remate de Males } 35.1
$$

VALÉRY. P. Estudios literarios. Tr. Juan Carlos Díaz de Atauri. Madrid: Visor, 1995.

VALÉRY. P. Eupalinos o el Arquitecto. In: El alma y la danza. Eupalinos o el Arquitecto. Tr. José Carner. Buenos Aires: Losada, 1944. p. 57-171.

VALÉRY. P. Lettres à quelques-uns. 7.․ㅡ. ed. París: Gallimard, 1952.

VALÉRY. P. Monsieur Teste. Tr. Salvador Elizondo. Barcelona: Montesinos, 1986.

VALÉRY. P. Cuvres. 2 vols. Ed. Jean Hytier. París: Gallimard, p. 1957-1960.

VALÉRY. P. Piezas sobre arte. Tr. José Luis Arántegui. Madrid: Visor, 1999.

VALÉRY. P. Política del espíritu. Tr. Ángel J. Battistessa. Buenos Aires: Losada, 1961.

VALÉRY. P. Tel quel. Tr. Nicanor Ancochea. Barcelona: Labor, 1977.

VALÉRY. P. Teoría poética y estética. Tr. Carmen Santos. Madrid: Visor, 1990. 